\title{
High Performance Liquid Chromatographic Enantioseparation of Chiral Bridged Polycyclic Compounds on Chiralcel OD-H and Chiralpak OT(+)
}

\author{
PAOLA PELUSO,${ }^{1 *}$ SERGIO COSSU, ${ }^{2 \star}$ FLAVIO MORETTO,${ }^{2}$ AND MAURO MARCHETTI ${ }^{1}$ \\ ${ }^{1}$ Istituto di Chimica Biomolecolare ICB CNR-sezione di Sassari, I-07040 Li Punti, Sassari, Italy \\ ${ }^{2}$ Dipartimento di Chimica, Università Ca' Foscari di Venezia, Venezia I-30123, Italy
}

\begin{abstract}
The HPLC enantiomeric separation of 29 racemic bridged polycyclic compounds was examined on commercially available Chiralcel OD-H and Chiralpak OT $(+)$ columns. The separations were evaluated under normal-phase mode (hexane containing mobile phase) for Chiralcel OD-H and under normal-phase as well as under reversed-phase mode (pure $\mathrm{MeOH}$, temperature $5^{\circ} \mathrm{C}$ ) for Chiralpak OT(+). Almost all compounds were resolved either on Chiralcel OD-H or on Chiralpak OT(+), in some cases on both. The use of trifluoroacetic acid (TFA), as modifier of the hexanic mobile phase, had a beneficial effect on the enantioseparation of some polar and acidic compounds on Chiralcel OD-H. The influence of small chemical structural modifications of the analytes on the enantioseparation behavior is discussed. A structure-retention relationship has been observed on both stationary phases. This chromatographic evaluation may provide some information about the chiral recognition mechanism: in the case of Chiralcel OD-H, hydrogen bonding, $\pi-\pi$ and distereoselective repulsive are supposed to be the major analyte-CSP interactions. In the case of Chiralpak OT(+), a reversed-phase enantioseparation could take place through hydrophobic interactions between the aromatic moiety of the analytes and the chiral propeller structure of the CSP. The synthesis of some unknown racemic bromobenzobicyclo[2.2.1] analytes is also described. Chirality 21:507-518, 2009. @ 2008 Wiley-Liss, Inc.
\end{abstract}

KEY WORDS: polysaccharide stationary phases; polymetacrylate stationary phases; enantiomeric separation; high performance liquid chromatography; bridged polycyclic compounds

\section{INTRODUCTION}

Bridged polycyclic compounds are widely used in several fields of organic chemistry. ${ }^{1-4}$ As part of our interest in the synthesis and reactivity of phenylsulfonyl bridged polycyclic compounds, we have recently prepared some enantiopure bicyclo[2.2.1] ketosulfones $^{5-7}$ and some bicyclo[2.2.1] alkyl-, alkenylsulfones, ${ }^{8}$ and bromobenzonorbornadienes, ${ }^{9,10}$ as racemates.

In this study, the HPLC direct enantioseparation of the bridged polycyclic compounds 1-25, (Figs. 1-3), using Chiralcel OD- ${ }^{11-13}$ (CSP1), a cellulose tris(3,5-dimethylphenylcarbamate)-type CSP, and Chiralpak OT $(+)^{14,15}$ (CSP2), a (+)-poly (triphenylmethylmethacrylate) [PTrMA]based CSP (Fig. 4), has been evaluated.

Currently, polysaccharide-based CSPs are the most used phases for HPLC enantioseparation, because of their versatility and durability. ${ }^{16}$ Chiralcel $\mathrm{OD}-\mathrm{H}$, in particular, has shown excellent resolving power for a variety of racemates containing polar functional groups. ${ }^{17}$ Among the synthetic polymers-based CSPs, the one-handed helical PTrMA exhibits a high chiral recognition for chiral aromatic hydrocarbons devoid of polar functional groups. To (C) 2008 Wiley-Liss, Inc. the best of our knowledge, although some enantiomeric resolution methods have been developed for simple chiral bicyclo[2.2.1] compounds, ${ }^{15,17}$ an extensive investigation of a family of such compounds on CSP1 and on CSP2 has never been reported.

This article explores the influence of the hexanic mobile phase composition on the enantiomeric separation on CSP1: in some cases, the use of a ternary mixture of solvents ( $n$-hexane/2-propanol/methanol), also containing trifluoroacetic acid (TFA) as an additive, improves the enantioseparation efficiency. Elutions on CSP2 have been carried out both under normal- as well as reversed-phase mode. The influence of the structural features of the race-

\footnotetext{
Contract grant sponsors: Fondo Sociale Europeo (MIS. D4), Regione Veneto and Università Ca' Foscari di Venezia.

${ }^{*}$ Correspondence to: Paola Peluso, Istituto di Chimica Biomolecolare ICB CNR-sezione di Sassari, Traversa La Crucca, 3, Regione Baldinca, I-07040 Li Punti, Sassari, Italy. E-mail: p.peluso@icb.cnr.it or Sergio Cossu, Dipartimento di Chimica, Università Ca’ Foscari di Venezia, Dorsoduro 2137, I-30123-Venezia, Italy. E-mail: cossu@unive.it

Received for publication 14 February 2008; Accepted 28 May 2008

DOI: $10.1002 /$ chir.20629

Published online 24 July 2008 in Wiley InterScience

(www.interscience.wiley.com).
} 
<smiles>O=C1C2C=CC(C2)[C@H]1S(=O)(=O)c1ccccc1</smiles>

1a endo $1 \mathrm{~b}$ exo<smiles>O=C1C2CCC(C2)[C@H]1S(=O)(=O)c1ccccc1</smiles>

2a endo $\mathbf{2 b}$ exo<smiles>O=C1C2CCC(C2)[C@H]1S(=O)(=O)c1ccccc1</smiles>

3a endo<smiles>COc1ccc(OC)c2c1C1CC2[C@@H](Oc2ccccc2)C1=O</smiles>

4

Fig. 1. Structures of ketosulfones 1-4.

mic analytes on the chiral separation is discussed: the enantioselectivity $(\alpha)$, the enantiomeric resolution $\left(R_{\mathrm{S}}\right)$ of the examined racemates and the capacity factor of the first eluting peak $\left(k_{1}\right)$ have been calculated and compared. On the basis of numerous experimental results, an empirical recognition model, for CSP1 and CSP2, is proposed that facilitates the suitable choice both of the CSP and the mobile phase, for the examined family of racemates or analogs. In addition, to explore the effect of the substituents on the enantiomeric separation, synthesis of some new racemic compounds such as aromatic ketosulfone 4 , tribromobenzonorbornenes 19,20 , and 23 , and dibromobenzonorbornadienes $\mathbf{2 4}$ and $\mathbf{2 5}$ was designed and carried out.

\section{MATERIALS AND METHODS Chemicals}

Racemic compounds $\left[(\mathbf{1}-\mathbf{3}),{ }^{5,6} \mathbf{5},{ }^{18}(\mathbf{6}, \mathbf{1 5}, \mathbf{1 6}, \mathbf{1 8}),{ }^{9}\right.$ $(\mathbf{7}, \mathbf{1 0 - 1 4}),{ }^{8} \mathbf{8}$ (Cossu, S. personal communication), $\mathbf{9},{ }^{7}$ $(\mathbf{1 7}, \mathbf{2 1}-\mathbf{2 2})^{19}$ ] were prepared according to the published procedures. The reagents were purchased from standard chemical suppliers and purified ${ }^{20}$ to match the reported physical and spectral data. The solvents were dried before use. Thin layer chromatography (TLC) was performed on silica gel plates (Si 60, Merck, Darmstadt, Germany). Flash chromatography was carried out on Merck silica gel $60(40-60 \mu \mathrm{m})$. NMR experiments were performed on spectrometers operating at 300 (Bruker Advance300) and at 400 (Varian Unity 400 ) $\mathrm{MHz}$ at ${ }^{1} \mathrm{H}$ nucleus and at 75 and $100 \mathrm{MHz}$ at ${ }^{13} \mathrm{C}$ nucleus. Chemical shifts ( $\delta$ ) are reported in parts per million (ppm) and are referenced to $\mathrm{SiMe}_{4}(0 \mathrm{ppm})$. Multiplicities are reported as broad (br), singlet $(s)$, doublet $(d)$, triplet $(t)$, quartet $(q)$, and multiplet $(m)$. Coupling constants $(D)$ are reported in Hz. Mass spectra were acquired on a Hewlett Packard GC MS model 5971 spectrometer at $70 \mathrm{eV}$, coupled with a Hewlett Packard model 5890 gas chromatograph equipped with a capillary column DB5 $(30 \mathrm{~m}, 0.25 \mu \mathrm{m})$.

\section{$(+)(-)-5,8$-Dimethoxy-1,4-methano-3-oxo-2-exo- phenylsulfonyl-1,2,3,4-tetrahydronaphthalene (4)}

A suspension of MeONa $(0.108 \mathrm{~g}, 2 \mathrm{mmol})$ in dry THF $(10 \mathrm{ml})$ was cooled to $0^{\circ} \mathrm{C}$ and a solution of 2,3-bis(phenylsulfonyl)-1,4-dihydro-5,8-dimethoxy-1,4-methanonaphthalene ${ }^{9}$ $26(0.482 \mathrm{~g}, 1 \mathrm{mmol})$ in THF $(10 \mathrm{ml})$ was slowly added. The mixture was stirred at room temperature for $5 \mathrm{~h}$, then $\mathrm{HCl}$ of $6 \mathrm{~N}(2 \mathrm{ml})$ was added. The mixture was stirred for $1 \mathrm{~h}$, washed with $\mathrm{H}_{2} \mathrm{O}$, extracted with $\mathrm{CH}_{2} \mathrm{Cl}_{2}(3 \times 40 \mathrm{ml})$, dried over $\mathrm{Na}_{2} \mathrm{SO}_{4}$ and concentrated in vacuo. Pure sam-<smiles>O=S(=O)(Oc1ccccc1)C1C2C=CC(C2=C(c2ccccc2)c2ccccc2)C1(Cl)c1ccccc1</smiles><smiles>O=S(=O)(Oc1ccccc1)C1=CC2CC1c1ccccc12</smiles>

6<smiles>CC(=O)N1C2C=CC1C(S(=O)(=O)c1ccccc1)=C2Br</smiles><smiles>O=S(=O)(O)C1=C(Br)C2C=CC1C2</smiles>

7<smiles>C=C1C2C=CC(C2)[C@H]1S(=O)(=O)c1ccccc1</smiles>

10a endo

10b exo<smiles>O=S(=O)(Oc1ccccc1)C1=C(Br)C2C=CC1O2</smiles><smiles>CCC/C=C1\C2C=CC(C2)C1S(=O)(=O)c1ccccc1</smiles>

11<smiles>CC1=C([SH](=O)(O)c2ccccc2)C2C=CC1C2</smiles><smiles>CCC1=C([SH](=O)(O)c2ccccc2)C2C=CC1C2</smiles><smiles>CCCCC1=C(S(=O)(=O)c2ccccc2)C2C=CC1C2</smiles>

Fig. 2. Structures of sulfones 5-14. 
<smiles>BrC1=CC2CC1c1ccccc12</smiles>

15<smiles>COc1ccc(OC)c2c1C1CCC2C(Br)C1</smiles><smiles>COc1cc2c(cc1OC)C1(Br)C(Br)CC2C1Br</smiles><smiles>COc1cc2c(cc1OC)C1CCC2C=C1Br</smiles>
17<smiles>BrC1=CC2CC1c1cc3ccccc3cc12</smiles>

18<smiles>COc1ccc(OC)c2c1C1(Br)C(Br)C(Br)C2(Br)C1Br</smiles><smiles>C[AsH2]C1=C(Br)C2C=CC1c1ccccc12</smiles><smiles>COc1ccc(OC)c2c1C1CC2C(SC)=C1Br</smiles><smiles>COc1cc2c(cc1OC)C1C2CC(Br)C1(Br)Br</smiles><smiles>COc1ccc(OC)c2c1C1C(Br)CC2(Br)C1Br</smiles><smiles></smiles>

Fig. 3. Structures of bromobenzobicyclo[2.2.1] derivatives 15-25.

ple of ketosulfone 4 ( $0.262 \mathrm{~g}$, 73\% yield) was obtained after purification by flash chromatography ( $n$-hexane/AcOEt in a 9:1 ratio): ${ }^{1} \mathrm{H}$ NMR (400 MHz, $\mathrm{CDCl}_{3}$ ) $\delta$ ppm: 2.32-2.39 $\left(m, 1 \mathrm{H}, \mathrm{H}_{9 \mathrm{a}}\right), 3.07\left(d t, 1 \mathrm{H}, J=10.4 \mathrm{~Hz}, J=1.6 \mathrm{~Hz}, \mathrm{H}_{9 \mathrm{~s}}\right)$, $3.45\left(d, 1 \mathrm{H}, J=3.2 \mathrm{~Hz}, \mathrm{H}_{4}\right), 3.92\left(d, 1 \mathrm{H}, J=1.6 \mathrm{~Hz}, \mathrm{H}_{1}\right)$, $4.46\left(d, 1 \mathrm{H}, J=1.6 \mathrm{~Hz}, \mathrm{H}_{2}\right), 6.62(s, 1 \mathrm{H}, \mathrm{Ar}), 6.64(s, 1 \mathrm{H}$, Ar), 7.52-7.68, 7.80-7.99 (series of $m, 5 \mathrm{H}, \mathrm{Ar}$ ); ${ }^{13} \mathrm{C}$ NMR (100 MHz, $\mathrm{CDCl}_{3}, 6 \mathrm{C}$ atoms omitted) $\delta \mathrm{ppm}: 41.35,46.80$, $53.14,55.87,56.11,68.10,111.52,128.78,128.85,129.05$, 133.97, 200.11.

\section{(+)(-)-1,4-Dihydro-5,8-dimethoxy-1,4-methano-1,2- exo-9-anti-tribromonaphthalene (19)}

A solution of $\mathrm{Br}_{2}(1.28 \mathrm{~g}, 8.0 \mathrm{mmol}, 0.4 \mathrm{ml})$ in $\mathrm{CCl}_{4}(5$ $\mathrm{ml}$ ) was rapidly added to a solution of 2-bromo-1,4-dihydro5,8-dimethoxy-1,4-methanonaphthalene $\mathbf{1 6}^{19}$ (2.27 g, 8.0 mmol) in $\mathrm{CCl}_{4}(20 \mathrm{ml})$, stirred under argon at reflux temperature. After $5 \mathrm{~min}$, the solvent was removed at reduced pressure, giving 19 (3.52 g, quantitative yield) as a chemically pure red oil: ${ }^{1} \mathrm{H}$ NMR $\left(400 \mathrm{MHz}, \mathrm{CDCl}_{3}\right) \delta \mathrm{ppm}: 2.35$ $\left(d d t, 1 \mathrm{H}, J=13.2 \mathrm{~Hz}, J=8.8 \mathrm{~Hz}, J=0.6 \mathrm{~Hz}, \mathrm{H}_{3 \text { endo }}\right), 3.03$ $\left(d t, 1 \mathrm{H}, J=13.2 \mathrm{~Hz}, J=4.0 \mathrm{~Hz}, \mathrm{H}_{3 \mathrm{exo}}\right), 3.68(d d d, 1 \mathrm{H}, J=$ $\left.4.0 \mathrm{~Hz}, \mathrm{~J}=1.6 \mathrm{~Hz}, J=0.6 \mathrm{~Hz}, \mathrm{H}_{4}\right), 3.77(s, 3 \mathrm{H}, \mathrm{OMe})$, $3.81(s, 3 \mathrm{H}, \mathrm{OMe}), 4.05(d d d, 1 \mathrm{H}, J=8.0 \mathrm{~Hz}, J=4.0 \mathrm{~Hz}, J$ $\left.=1.6 \mathrm{~Hz}, \mathrm{H}_{2 \mathrm{endo}}\right), 4.22(d d, 1 \mathrm{H}, J=1.6 \mathrm{~Hz}, J=1.6 \mathrm{~Hz}$, $\left.\mathrm{H}_{9}\right), 6.72(s, 1 \mathrm{H}, \mathrm{Ar}), 6.73(s, 1 \mathrm{H}, \mathrm{Ar}) ;{ }^{13} \mathrm{C} \mathrm{NMR}(100 \mathrm{MHz}$, $\left.\mathrm{CDCl}_{3}\right) \delta$ ppm: $38.69,44.48,51.42,55.90,64.15,112.15$, $112.45,129.12,132.15,146.78,148.29 ; \mathrm{m} / z$ (\%): 442 (8) $\left[\mathrm{M}^{+}+2\right], 440(9)\left[\mathrm{M}^{+}\right], 361$ (13), 253 (92), 201 (29), 171 (24), 115 (31), 97 (58), 69 (67), 57 (100).

\section{(+)(-)-1,4-Dihydro-1,9-anti-dibromo-5,8-dimethoxy- 1,4-methanonaphthalene (24)}

A solution of 19 (3.52 g, $8.0 \mathrm{mmol})$ in THF $(15 \mathrm{ml})$, stirred under argon at room temperature, was treated with a solution of $t$-BuOK $(2.69 \mathrm{~g}, 24 \mathrm{mmol})$ in the same solvent $(20 \mathrm{ml})$. The resulting brown mixture was then stirred at reflux temperature for additional $3 \mathrm{~h}$. After the mixture had cooled to room temperature, the solvent was removed under reduced pressure and the residue was diluted with $\mathrm{Et}_{2} \mathrm{O}(50 \mathrm{ml})$. The organic phase was washed with $\mathrm{H}_{2} \mathrm{O}(3$ $\times 50 \mathrm{ml})$ and brine $(2 \times 30 \mathrm{ml})$, dried $\left(\mathrm{MgSO}_{4}\right)$ and concentrated under reduced pressure. The residue was purified by flash chromatography (petroleum ether/AcOEt in a 9.5:0.5 ratio) (2.30 g, 80\% yield): ${ }^{1} \mathrm{H}$ NMR $(400 \mathrm{MHz}$, $\left.\mathrm{CDCl}_{3}\right) \delta$ ppm: $3.78(s, 3 \mathrm{H}, \mathrm{OMe}), 3.81(s, 3 \mathrm{H}, \mathrm{OMe}), 4.31$ $\left(d d d, 1 \mathrm{H}, J=3.2 \mathrm{~Hz}, J=1.2 \mathrm{~Hz}, J=0.8 \mathrm{~Hz}, \mathrm{H}_{4}\right), 4.53(d t$, $\left.1 \mathrm{H}, J=1.2 \mathrm{~Hz}, J=0.8 \mathrm{~Hz}, \mathrm{H}_{9}\right), 6.61(d t, 1 \mathrm{H}, J=5.2 \mathrm{~Hz}, J$ $\left.=0.8 \mathrm{~Hz}, \mathrm{H}_{2}\right), 6.64(s, 2 \mathrm{H}, \mathrm{Ar}), 6.66(s, 2 \mathrm{H}, \mathrm{Ar}), 6.69$ (ddd, $\left.1 \mathrm{H}, J=5.2 \mathrm{~Hz}, J=3.2 \mathrm{~Hz}, J=0.8 \mathrm{~Hz}, \mathrm{H}_{3}\right) ;{ }^{13} \mathrm{C}$ NMR $(100$ $\mathrm{MHz}, \mathrm{CDCl}_{3}$ ) $\delta$ ppm: 51.60, 56.00, 57.08, 66.15, 82.09, $111.21,112.91,133.14,134.56,139.86,142.76,147.75$, 149.27; $m / z$ (\%): $362(5)\left[\mathrm{M}^{+}+4\right], 360(10)\left[\mathrm{M}^{+}+2\right]$, $358(5)\left[\mathrm{M}^{+}\right], 279$ (98), 249 (34), 171 (73), 114 (42), 97 (63), 69 (75), 55 (100).

\section{(+)(-)-1,4-Dihydro-6,7-dimethoxy-1,4-methano- 1,2-exo-9-anti-tribromonaphthalene (20)}

A solution of $\mathrm{Br}_{2}(0.30 \mathrm{~g}, 1.9 \mathrm{mmol}, 0.1 \mathrm{ml})$ in $\mathrm{CCl}_{4}(3$ $\mathrm{ml}$ ) was rapidly added to a solution of 2-bromo-1,4-dihydro-

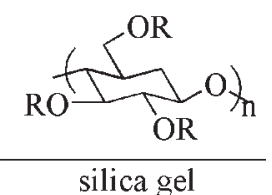

Chiralcel OD-H (CSP1) $\mathrm{R}=-\mathrm{CONH}-\left(3,5-\mathrm{Me}_{2}\right)-\mathrm{Ph}$

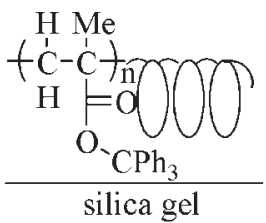

Chiralpak OT(+) (CSP2)
Fig. 4. Structures of CSP1 and CSP2. 
6,7-dimethoxy-1,4-methanonaphthalene $\mathbf{1 7}^{19}$ (0.53 g, 1.9 mmol) in $\mathrm{CCl}_{4}(10 \mathrm{ml})$, stirred under argon at reflux temperature. After $5 \mathrm{~min}$, the solvent was removed under reduced pressure, furnishing $\mathbf{2 0}(0.75 \mathrm{~g}, 90 \%$ yield $)$ as a white solid: ${ }^{1} \mathrm{H}$ NMR $\left(400 \mathrm{MHz}, \mathrm{CDCl}_{3}\right) \delta \mathrm{ppm}: 2.34(d d t$, $\left.1 \mathrm{H}, J=13.2 \mathrm{~Hz}, J=8.0 \mathrm{~Hz}, J=1.2 \mathrm{~Hz}, \mathrm{H}_{3 \text { endo }}\right), 3.04(d t$, $\left.1 \mathrm{H}, J=13.2 \mathrm{~Hz}, J=4.4 \mathrm{~Hz}, \mathrm{H}_{3 \mathrm{exo}}\right), 3.42-3.47\left(m, 1 \mathrm{H}, \mathrm{H}_{4}\right)$, 3.87 (s, 3H, OMe), 3.85-3.92 ( $\left.m, 1 \mathrm{H}, \mathrm{H}_{2 \text { endo }}\right), 3.90(s, 3 \mathrm{H}$, OMe), $4.22\left(d d, 1 \mathrm{H}, J=2.8 \mathrm{~Hz}, J=1.2 \mathrm{~Hz}, \mathrm{H}_{9}\right), 6.75(s$, $1 \mathrm{H}, \mathrm{Ar}), 6.99$ (s, $1 \mathrm{H}, \mathrm{Ar}) ;{ }^{13} \mathrm{C} \mathrm{NMR}\left(100 \mathrm{MHz}, \mathrm{CDCl}_{3}\right) \delta$ ppm: 39.09, 48.44, 51.66, 56.25, 62.66, 69.01, 105.09, $105.82,133.96,134.38,148.90,149.76$.

\section{$(+)(-)-1,4-D i h y d r o-6,7-d i m e t h o x y-1,4-m e t h a n o-$ 2,2,3-endo-tribromonaphthalene (23)}

$\mathrm{A} \mathrm{CCl}_{4}(5 \mathrm{ml})$ solution of compound $\mathbf{1 7}(0.280 \mathrm{~g}, 1$ mmol) and $\mathrm{CBrCl}_{2} \mathrm{CBrCl}_{2}(0.48 \mathrm{~g}, 1.5 \mathrm{mmol})$ was irradiated with a $250 \mathrm{~W}$ halogen lamp, for $3 \mathrm{~h}$ at reflux temperature, while stirring. The solvent was removed at reduced pressure and the residue was purified by flash chromatography (petroleum ether/AcOEt in a 9:1 ratio). An exo/endo mixture of 23 was obtained ( $0.167 \mathrm{~g}, 38 \%$ yield). A pure analytical sample of endo-tribromo derivative $23(12 \mathrm{mg})$ was obtained after purification by flash chromatography, under the reported conditions: 3-exo-23 ${ }^{1} \mathrm{H}$ NMR $(400$ $\left.\mathrm{MHz}, \mathrm{CDCl}_{3}\right) \delta$ ppm: $2.21(d d t, 1 \mathrm{H}, J=10.0 \mathrm{~Hz}, J=2.8$ $\left.\mathrm{Hz}, J=1.6 \mathrm{~Hz}, \mathrm{H}_{9}\right), 2.71(d t, 1 \mathrm{H}, J=10.0 \mathrm{~Hz}, J=1.6 \mathrm{~Hz}$, $\left.\mathrm{H}_{9}\right), 3.49\left(t, 1 \mathrm{H}, J=1.6 \mathrm{~Hz}, \mathrm{H}_{4}\right), 3.85(s, 3 \mathrm{H}, \mathrm{OMe}), 3.86$ $(s, 3 \mathrm{H}, \mathrm{OMe}), 4.04\left(t, 1 \mathrm{H}, J=1.6 \mathrm{~Hz}, \mathrm{H}_{1}\right), 4.39(d, 1 \mathrm{H}, J=$ $\left.2.8 \mathrm{~Hz}, \mathrm{H}_{3}\right), 6.81(s, 1 \mathrm{H}, \mathrm{Ar}), 6.95(\mathrm{~s}, 1 \mathrm{H}, \mathrm{Ar}) ; 3-e n d o-23{ }^{1} \mathrm{H}$ NMR $\left(400 \mathrm{MHz}, \mathrm{CDCl}_{3}\right) \delta$ ppm: $2.31(d t, 1 \mathrm{H}, J=10.4 \mathrm{~Hz}$, $\left.J=1.6 \mathrm{~Hz}, \mathrm{H}_{9}\right), 2.61\left(d t, 1 \mathrm{H}, J=10.4 \mathrm{~Hz}, J=1.6 \mathrm{~Hz}, \mathrm{H}_{9}\right)$, $3.51\left(d d, 1 \mathrm{H}, J=3.6 \mathrm{~Hz}, J=1.6 \mathrm{~Hz}, \mathrm{H}_{4}\right), 3.84(s, 6 \mathrm{H}$, OMe), $4.05\left(t, 1 \mathrm{H}, J=1.6 \mathrm{~Hz}, \mathrm{H}_{1}\right), 5.29(d, 1 \mathrm{H}, J=3.6 \mathrm{~Hz}$, $\left.\mathrm{H}_{3}\right), 6.82(s, 1 \mathrm{H}, \mathrm{Ar}), 6.90(s, 1 \mathrm{H}, \mathrm{Ar})$; endo/exo mixture of isomers ${ }^{13} \mathrm{C}$ NMR (100 MHz, $\left.\mathrm{CDCl}_{3}\right) \delta$ ppm: 46.11, 47.04, $52.29,55.29,56.02,56.17,64.63,65.04,69.70,69.94,105.25$, $108.27,108.68,109.07,134.25,135.09,135.49,136.42$, 147.99, 148.11, 148.21, 148.92 .

\section{(+)(-)-1,9-anti-Dibromo-1,4-dihydro-6,7-dimethoxy- 1,4-methanonaphthalene (25)}

A solution of 1,4-dihydro-6,7-dimethoxy-1,4-methano2,2,3-endo-tribromonaphthalene $\mathbf{2 3}$ as mixture of exo/endo isomers $(0.750 \mathrm{~g}, 1.7 \mathrm{mmol})$ in THF $(10 \mathrm{ml})$, stirred under argon at room temperature, was treated with a solution of $t$-BuOK $(0.570 \mathrm{~g}, 5.1 \mathrm{mmol})$ in the same solvent $(20 \mathrm{ml})$. The resulting brown mixture was then stirred at reflux temperature for additional $3 \mathrm{~h}$. After the mixture had cooled to room temperature, the solvent was removed under reduced pressure and the residue was diluted with $\mathrm{Et}_{2} \mathrm{O}(50 \mathrm{ml})$. The organic phase was washed with $\mathrm{H}_{2} \mathrm{O}(3$ $\times 50 \mathrm{ml})$ and brine $(2 \times 30 \mathrm{ml})$, dried $\left(\mathrm{MgSO}_{4}\right)$ and concentrated under reduced pressure. The residue was purified by flash chromatography (petroleum ether/AcOEt in a 9.5:0.5 ratio) $\left(0.275 \mathrm{~g}, 45 \%\right.$ yield): ${ }^{1} \mathrm{H}$ NMR $(400 \mathrm{MHz}$, $\left.\mathrm{CDCl}_{3}\right) \delta$ ppm: $3.86(s, 3 \mathrm{H}, \mathrm{OMe}), 3.91(s, 3 \mathrm{H}, \mathrm{OMe}), 4.07$ $\left(d d d, 1 \mathrm{H}, J=3.2 \mathrm{~Hz}, J=1.2 \mathrm{~Hz}, J=0.8 \mathrm{~Hz}, \mathrm{H}_{4}\right), 4.45(d t$, Chirality DOI 10.1002/chir $\left.1 \mathrm{H}, J=1.2 \mathrm{~Hz}, J=0.8 \mathrm{~Hz}, \mathrm{H}_{9}\right), 6.55(d t, 1 \mathrm{H}, J=6.0 \mathrm{~Hz}, J$ $\left.=0.8 \mathrm{~Hz}, \mathrm{H}_{2}\right), 6.71(d d d, 1 \mathrm{H}, J=6.0 \mathrm{~Hz}, J=3.2 \mathrm{~Hz}, J=$ $\left.0.8 \mathrm{~Hz}, \mathrm{H}_{3}\right), 6.88(s, 1 \mathrm{H}, \mathrm{Ar}), 7.05(s, 1 \mathrm{H}, \mathrm{Ar}) . m / z(\%)=$ $358(4)\left[\mathrm{M}^{+}\right], 360(8)\left[\mathrm{M}^{+}+2\right], 362(4)\left[\mathrm{M}^{+} \cdot+4\right], 279$ (100), 281 (98), 263 (6), 235 (19), 157 (13), 114 (27), $57(21)$.

\section{Chromatography}

An HPLC system Shimadzu LC-10AT Vp, equipped with a Shimadzu $20 \mu$ l sample loop, an UV-Vis Shimadzu SPD$10 \mathrm{~A} \mathrm{Vp}$ spectrophotometric detector operating at $254 \mathrm{~nm}$ and a Millenium for Windows 95 integrator, was employed. Chiralcel OD-H $(250 \mathrm{~mm} \times 4.6 \mathrm{~mm})(5 \mu \mathrm{m})$ (cellulose tris-3,5-dimethylphenylcarbamate) (CSP1) and Chiralpak OT $(+)(250 \mathrm{~mm} \times 4.6 \mathrm{~mm})(10 \mu \mathrm{m})\{(+)$-poly (triphenylmethylmethacrylate) [PTrMA]\} (CSP2) coated on silica gel (Daicel, Tokyo, Japan) were used. Analyses were performed in isocratic mode. HPLC-grade solvents were supplied by Fluka (Switzerland) and by Riedel de Haën (Seelze, Germany). Trifluoroacetic acid (TFA) was purchased from Fluka (Switzerland). n-Hexane 100\%, nhexane/2-propanol $=90 / 10, n$-hexane/2-propanol/methanol $=91 / 6 / 3$ or $n$-hexane $/ 2$-propanol $/$ methanol $=91 / 6 / 3$ (with $0.1 \%$ of trifluoroacetic acid) on Chiralcel OD-H and methanol $100 \%$ or $n$-hexane/2-propanol $=90 / 10$ on Chiralpak OT(+) were used as mobile phases and were prepared in a volume/volume relation and degassed under He flow before use. Chromatographic resolutions were performed at $25^{\circ} \mathrm{C}$, if not otherwise specified. The retention factor $(k)$ was determined as $k=\left(t_{\mathrm{R}}-t_{0}\right) / t_{0}$, where $t_{\mathrm{R}}$ is the retention time for the eluted enantiomeric compound. The enantioselectivity factor $(\alpha)$ was calculated as $\alpha=k_{2} / k_{1}$. The enantiomeric resolution factor $\left(R_{\mathrm{S}}\right)$ was determined as $2\left(t_{\mathrm{R} 2}-t_{\mathrm{R} 1}\right) /\left(W_{1}+W_{2}\right)$ where $t_{\mathrm{R}}$ and $W$ are the retention time and the basewidth of peak of the eluted enantiomer, respectively. The peak of the solvent front was considered to be equal to the dead time $\left(t_{0}\right)$, which was taken from each run. For ketosulfones 1, 2, and 3, the absolute configuration and the sign of the optical rotation were confirmed by injecting pure enantiomers of known configuration. The eluted samples of ketosulfones $\mathbf{1}, \mathbf{2}$, and $\mathbf{3}$ consist in an endo/exo epimeric mixture. In fact, in the stereoselective desymmetrization of the corresponding bis(phenylsulfonyl)alkenes, enantiopure ketosulfones are synthesized as epimeric mixtures, ${ }^{5-7}$ which can be conveniently resolved in a single elution.

\section{RESULTS AND DISCUSSION Synthesis of Ketosulfone 4}

Racemic ketosulfones 1-4 were synthesized as reported elsewhere. ${ }^{5,21}$ For our purpose, the hitherto unknown compound 4 features an interesting structure for our purpose, because of the aromatic $\pi$-basic moiety which bears two methoxy groups at 5 and 8 positions. As shown in Scheme 1, the Michael addition of two equivalents of alcoholate to 2,3-bis(phenylsulfonyl)-5,8-dimethoxybenzonorbornadiene 26 furnishes an intermediate mixture of the corresponding enolether (i) and ketal (ii) (Scheme 1) 


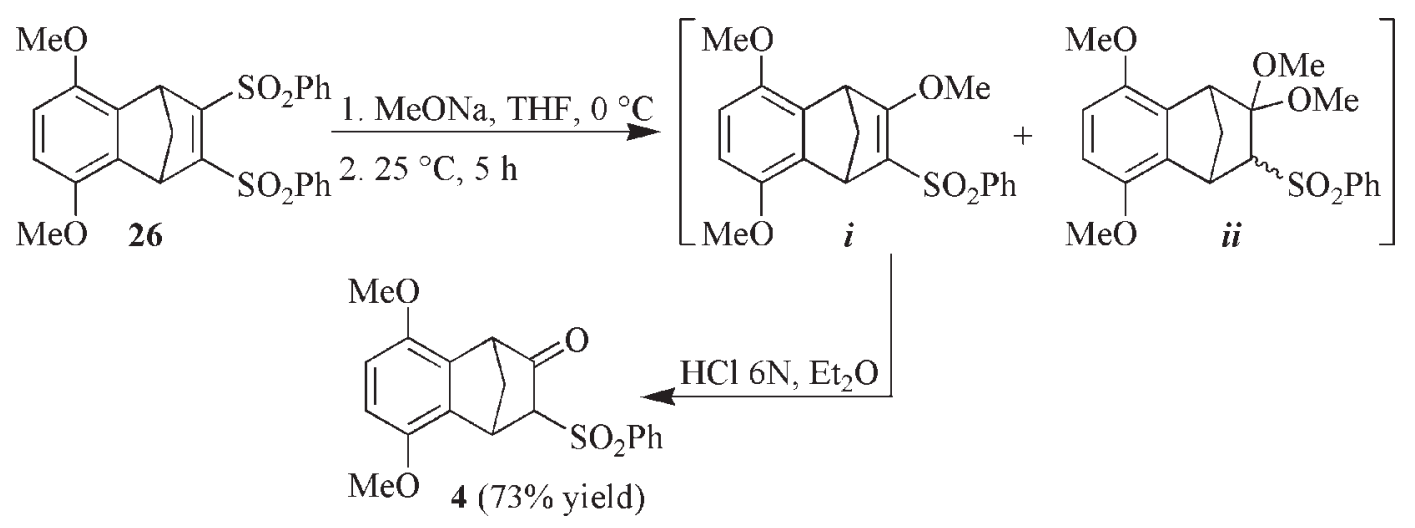

Scheme 1. Synthesis of ketosulfone 4.

which was directly treated with $\mathrm{HCl}$ of $6 \mathrm{~N}$ at room temperature to obtain the racemic ketosulfone 4 (73\% yield).

\section{Bromination of Dimethoxybenzonorbornadiene Derivatives: Synthesis of Analytes 19, 20, 23-25}

Compounds 19, 20, 23, 24, and 25, bearing bromine substituents at the 3-endo, bridgehead and anti methanebridge positions, respectively, were designed and prepared by a properly conceived synthesis. Our goal was to estimate the influence of the enhanced steric hindrance on the enantiomeric separation. A careful evaluation of the mechanisms regulating the bromination processes of bridged polymeric alkenes, ${ }^{22-24}$ allowed us to prepare compounds 19, 20, 24, and 25: bromination was carried out under conditions which favor the formation of WagnerMeerwein rearranged products, through the intermediancy of nonclassical carbocations. In the case of 2bromo-5,8-dimethoxybenzonorbornadiene $\mathbf{1 6}$, the reaction with bromine in $\mathrm{CCl}_{4}$ at reflux temperature provided the desired rearranged 1,2,9-tribromo derivative $\mathbf{1 9}$ in quantitative yield. Derivatives $\mathbf{1 9}$ was then dehydrobrominated by treating it with $t$-BuOK in refluxing THF to afford the dibromo derivatives 24 (80\% yield) (Scheme 2 ).

Under free-radical conditions ( $250 \mathrm{~W}$ halogen light), the bromination of 2-bromo-6,7-benzonorbornadiene $\mathbf{1 7}$ (Scheme 3) was performed using 1,2-dibromotetrachloroethane in $\mathrm{CCl}_{4}$ solution, affording tribromo derivatives 23, as an endo/exo mixture (38\% yield).

As shown in Scheme 3, the reaction of $\mathbf{1 7}$ with a $\mathrm{CCl}_{4}$ solution of bromine leads to the formation of $\mathbf{2 0}$ which, upon treatment with $t$-BuOK in refluxing THF, furnishes 25 (45\% yield).

\section{Chromatographic Screening}

The results obtained on CSP1 and CSP2 are given in Tables 1-3. The systematic chromatographic pool of analyses are divided in three sets of experiments, involving ketosulfones 1-4 (Table 1), sulfones 5-14 (Table 2), and bromobenzobicyclo[2.2.1] derivatives 15-25 (Table 3), respectively. Ketosulfones $\mathbf{3 a}, \mathbf{3 b}$, and $\mathbf{4}$, bis(sulfone) $\mathbf{5}$, sulfones $\mathbf{7}, \mathbf{8}, \mathbf{9}$, and $\mathbf{1 0 a}$, and bromoderivatives $\mathbf{1 7}, \mathbf{1 9}, \mathbf{2 0}$, and $\mathbf{2 3}$ were analyzed only on CSP1. Sulfone 13 and bromoderivative 18 were analyzed only on CSP2. The remaining compounds were tested both on CSP1 and on CSP2. Twenty-three of 29 screened compounds showed selectivity values equal or above 1.2 and enantioresolution values equal or above 1.0. Ketosulfones $\mathbf{3 a}, \mathbf{3 b}$, and $\mathbf{4}$, bis(sulfone) $\mathbf{5}$, sulfone $\mathbf{1 0 a}$, and bromoderivatives $16,17,19,22,23,24$, and 25 , which contain polar functional groups in the polycyclic skeleton, gave good selectivity on CSP1 using hexanebased mobile phases. Sulfones 10b, 12, 13, and 14, bromoderivatives 15, 18, and 21 are less polar and were satisfactorily separated on CSP2 eluting with methanol. Only two compounds, 7 (Table 2, entry 25) and 20 (Table 3, entry 45), were unresolved both on CSP1 and on CSP2.

\section{Influence of the Mobile Phases on the Enantioseparation and the Enantioresolution}

As reported, ${ }^{17}$ a mixture of $n$-hexane/2-propanol $=90 /$ 10 is the most recommended eluent, suitable to achieve efficient separation on CSP1: in fact, good enantioselectivity and resolution factor $\left(\alpha=1.2, R_{\mathrm{S}}=2.0\right)$ (Table 1 , entry 1$)$ were obtained for ketosulfone 1a. In this study, the type<smiles>COc1ccc(OC)c2c1C1C=C(Br)C2C1(Br)Br</smiles>

Scheme 2. The bromination-dehydrobromination of $\mathbf{1 6}$. 
<smiles>COc1cc2c(cc1OC)C1(Br)C(Br)C(Br)C2(Br)c2cc(OC)c(OC)cc2C1(Br)C(Br)(Br)C(C)(C)C(Br)(Br)C(Br)(Br)Br</smiles><smiles>CC(C)(C(Cl)(Cl)Cl)[Ge](C)(C)C(Cl)(Cl)Cl</smiles><smiles>COc1cc2c(cc1OC)C1CC2C(Br)[C@@H]1Br</smiles>

endo exo-23 (38\% yield)

endo-23

Scheme 3. The bromination-dehydrobromination of 17 .

and the percentage of alcoholic modifier in the mobile phase were varied in order to optimize the efficiency of the analyses. The use of methanol as the alcoholic modifier favors the solubility of samples and enhances the polarity of the mobile phase, by weakening the hydrogen bonds. Moreover, the addition of TFA (0.1\%), as acidic modifier of the mobile phase, usually contributes to an increase of the peak resolution for compounds containing active hydrogens. ${ }^{11}$ High retention factors and a slight increase in resolution $\left(k_{1}=8.5, R_{\mathrm{S}}=2.3\right)$ (entry 2) were observed for ketosulfone 1a when a ternary $n$-hexane/2- propanol/methanol mobile phase containing a $3 \% \mathrm{v} / \mathrm{v}$ in methanol was used. An improved enantioselectivity and resolution ( $\left.\alpha=1.3, R_{\mathrm{S}}=2.9\right)$ (entry 3$)$ were observed when $0.1 \%$ TFA was added to the ternary mobile phase. Under these conditions, the retention factor substantially decreases $\left(k_{1}=4.9\right)$. In the case of ketosulfone $\mathbf{1 b}$ (entries 6, 7 and 8), the use of methanol and TFA does not influence the enantioselectivity and the resolution values, but only contributes to a decrease of the retention factor $\left(k_{1}=3.2\right.$ versus 4.8$)$. These results seem to suggest greater hydrogen bond ability for $\mathbf{1 a}$ than $\mathbf{1 b}$ (Fig. 5).

TABLE 1. HPLC behavior of the racemic compounds 1-4 on CSP1 and/or CSP2

\begin{tabular}{|c|c|c|c|c|c|c|c|c|c|}
\hline Entry & Compounds & CSPs & Mobile phase $e^{a, b}$ & $F R^{\mathrm{c}}$ & $t_{\mathrm{R} 1}(\min )$ & $t_{\mathrm{R} 2}(\min )$ & $k_{1}^{\mathrm{d}}$ & $\alpha^{\mathrm{e}}$ & $R_{\mathrm{s}}$ \\
\hline 1 & 1a & 1 & Hex:IPA (90:10) & 0.8 & $25.2(-)$ & $29.9(+)$ & 5.5 & 1.2 & 2.0 \\
\hline 2 & $1 \mathbf{a}$ & 1 & Hex:IPA:MeOH (91:6:3) & 0.8 & $36.7(-)$ & $44.3(+)$ & 8.5 & 1.2 & 2.3 \\
\hline 3 & $1 \mathbf{a}$ & 1 & Hex:IPA:MeOH (91:6:3) with 0.1\% TFA & 0.8 & $22.9(-)$ & $27.9(+)$ & 4.9 & 1.3 & 2.9 \\
\hline 4 & $1 \mathbf{a}$ & 2 & Hex:IPA (90:10) & 0.5 & $29.7(-)$ & $50.9(+)$ & 3.4 & 1.9 & 4.3 \\
\hline 5 & $1 \mathbf{a}$ & 2 & $\mathrm{MeOH} 100 \%$ & 0.7 & $11.3(-)$ & $39.8(+)$ & 2.2 & 4.7 & 9.2 \\
\hline 6 & $1 \mathbf{b}$ & 1 & Hex:IPA (90:10) & 0.8 & $17.1(+)$ & $19.9(-)$ & 3.4 & 1.2 & 2.1 \\
\hline 7 & $1 \mathrm{~b}$ & 1 & Hex:IPA:MeOH (91:6:3) & 0.8 & $22.4(+)$ & $26.3(-)$ & 4.8 & 1.2 & 2.0 \\
\hline 8 & $\mathbf{1 b}$ & 1 & Hex:IPA:MeOH (91:6:3) with 0.1\% TFA & 0.8 & $16.2(+)$ & $18.4(-)$ & 3.2 & 1.2 & 2.0 \\
\hline 9 & $1 \mathbf{b}$ & 2 & Hex:IPA (90:10) & 0.5 & $33.9(-)$ & $43.3(+)$ & 4.0 & 1.3 & 3.0 \\
\hline 10 & 1b & 2 & $\mathrm{MeOH} 100 \%$ & 0.7 & $11.3(-)$ & $15.6(+)$ & 2.2 & 1.5 & 2.8 \\
\hline 11 & $2 a$ & 1 & Hex:IPA:MeOH (91:6:3) & 0.8 & $34.8(+)$ & $38.8(-)$ & 8.0 & 1.1 & 1.4 \\
\hline 12 & $2 a$ & 2 & Hex:IPA (90:10) & 0.5 & $30.4(-)$ & $42.2(+)$ & 3.5 & 1.5 & 4.2 \\
\hline 13 & $\mathbf{2 a}$ & 2 & $\mathrm{MeOH} 100 \%$ & 0.7 & $14.4(+)$ & $16.8(-)$ & 3.1 & 1.2 & \\
\hline 14 & $2 b$ & 1 & Hex:IPA:MeOH (91:6:3) & 0.8 & 26.3 & & 5.8 & $N S^{f}$ & \\
\hline 15 & $2 b$ & 2 & Hex:IPA (90:10) & 0.5 & $34.6(+)$ & $49.7(-)$ & 4.1 & 1.5 & 3.9 \\
\hline 16 & $2 b$ & 2 & $\mathrm{MeOH} 100 \%$ & 0.7 & $13.2(-)$ & $23.0(+)$ & 2.8 & 2.0 & \\
\hline 17 & $3 \mathbf{a}$ & 1 & Hex:IPA:MeOH (91:6:3) & 0.8 & $22.0(+)$ & $24.6(-)$ & 4.7 & 1.1 & 1.0 \\
\hline 18 & $\mathbf{3 a}$ & 1 & Hex:IPA:MeOH (91:6:3) with 0.1\% TFA & 0.8 & $13.9(+)$ & $16.2(-)$ & 2.6 & 1.2 & 1.8 \\
\hline 19 & $\mathbf{3 b}$ & 1 & Hex:IPA:MeOH (91:6:3) & 0.8 & $40.7(-)$ & $59.0(+)$ & 9.5 & 1.5 & 3.1 \\
\hline 20 & $3 \mathbf{b}$ & 1 & Hex:IPA:MeOH (91:6:3) with 0.1\% TFA & 0.8 & $21.3(-)$ & $23.7(+)$ & 4.5 & 1.1 & 1.5 \\
\hline 21 & 4 & 1 & Hex:IPA:MeOH (91:6:3) with 0.1\% TFA & 0.8 & 18.6 & 25.1 & 3.8 & 1.4 & 3.2 \\
\hline
\end{tabular}

${ }^{a} \mathrm{Hex}$, hexane; IPA, 2-propanol; $\mathrm{MeOH}$, methanol; TFA, trifluoroacetic acid.

${ }^{\mathrm{b}}$ Analyses on CSP2, using pure $\mathrm{MeOH}$ as eluant, were performed at $5^{\circ} \mathrm{C}$.

${ }^{C}$ Flow rate $(\mathrm{ml} / \mathrm{min}) ; F R=0.8, t_{0}=3.9 \mathrm{~min}$ for OD-II column; $F R=0.5, t_{0}=6.8 \mathrm{~min} ; F R=0.7, t_{0}=3.5 \mathrm{~min}$ for OT $(+)$ column.

${ }^{\mathrm{d}}$ Retention factor of the first-eluted enantiomer.

eSeparation factor.

${ }^{\mathrm{f}}$ Not separated.

Chirality DOI 10.1002/chir 
TABLE 2. HPLC behavior of the racemic compounds 5-14 on CSP1 and/or CSP2

\begin{tabular}{|c|c|c|c|c|c|c|c|c|c|}
\hline Entry & Compounds & CSPs & Mobile phase $^{\mathrm{a}, \mathrm{b}}$ & $F R^{\mathrm{c}}$ & $t_{\mathrm{R} 1}(\min )$ & $t_{\mathrm{R} 2}(\min )$ & $k_{1}^{\mathrm{d}}$ & $\alpha^{\mathrm{e}}$ & $R_{\mathrm{s}}$ \\
\hline 22 & 5 & 1 & Hex:IPA:MeOH (91:6:3) & 0.8 & 34.7 & 43.2 & 8.0 & 1.3 & 2.4 \\
\hline 23 & 6 & 1 & Hex:IPA:MeOH (91:6:3) & 0.8 & 14.8 & 15.5 & 2.8 & 1.1 & 0.6 \\
\hline 24 & 6 & 2 & $\mathrm{MeOH} \mathrm{100 \%}$ & 0.7 & 8.3 & 8.6 & 1.4 & 1.1 & 0.2 \\
\hline 25 & 7 & 1 & Hex:IPA (90:10) & 0.5 & 15.7 & & 1.3 & $\mathrm{NS}^{\mathrm{f}}$ & \\
\hline 26 & 8 & 1 & Hex:IPA (90:10) & 0.8 & 20.0 & 21.1 & 4.2 & 1.1 & 0.7 \\
\hline 27 & 9 & 1 & Hex:IPA (90:10) & 0.8 & 26.5 & 29.2 & 5.8 & 1.1 & 1.0 \\
\hline 28 & $10 a$ & 1 & Hex:IPA:MeOH (91:6:3) & 0.8 & 10.5 & 11.6 & 1.7 & 1.2 & 1.1 \\
\hline 29 & $10 \mathrm{~b}$ & 1 & Hex:IPA:MeOH (91:6:3) & 0.8 & 9.2 & 9.6 & 1.4 & 1.1 & 0.6 \\
\hline 30 & $10 \mathrm{~b}$ & 2 & $\mathrm{MeOH} 100 \%$ & 0.5 & 12.7 & 17.0 & 2.2 & 1.5 & 2.5 \\
\hline 31 & 11 & 1 & Hex:IPA:MeOH (91:6:3) & 0.8 & 8.1 & 8.6 & 1.1 & 1.1 & 0.8 \\
\hline 32 & 11 & 2 & $\mathrm{MeOH} 100 \%$ & 0.5 & 13.8 & 15.7 & 2.5 & 1.2 & 0.9 \\
\hline 33 & 12 & 1 & Hex:IPA:MeOH (91:6:3) & 0.8 & 8.7 & 8.9 & 1.2 & 1.0 & 0.3 \\
\hline 34 & 12 & 2 & $\mathrm{MeOH} 100 \%$ & 0.5 & 10.0 & 11.0 & 1.5 & 1.2 & 1.0 \\
\hline 35 & 13 & 2 & MeOH 100\% & 0.5 & 10.9 & 13.0 & 1.8 & 1.3 & 1.2 \\
\hline 36 & 14 & 1 & Hex:IPA:MeOH (91:6:3) & 0.8 & 6.7 & & 0.7 & $N S^{f}$ & \\
\hline 37 & 14 & 2 & $\mathrm{MeOH} 100 \%$ & 0.5 & 12.0 & 13.7 & 2.0 & 1.2 & 1.1 \\
\hline
\end{tabular}

${ }^{a} \mathrm{Hex}$, hexane; IPA, 2-propanol; MeOH, methanol; TFA, trifluoroacetic acid.

${ }^{\mathrm{b}}$ Analyses on CSP2, using pure $\mathrm{MeOH}$ as eluant, were performed at $5{ }^{\circ} \mathrm{C}$.

${ }^{c}$ Flow rate $(\mathrm{ml} / \mathrm{min}) ; F R=0.8, t_{0}=3.9 \mathrm{~min} ; F R=0.5, t_{0}=6.8 \mathrm{~min}$ for OD-H column; $F R=0.5, t_{0}=3.9 \mathrm{~min} ; F R=0.7, t_{0}=3.5 \mathrm{~min}$ for OT $(+)$ column.

${ }^{\mathrm{d}}$ Retention factor of the first-eluted enantiomer.

'Separation factor.

${ }^{\mathrm{f}}$ Not separated.

The use of TFA improves both the enantioselectivity and the enantioresolution ( $\alpha=1.2$ vs. $1.1, R_{\mathrm{s}}=1.8$ vs. 1.0) for compound 3a (entries 17 and 18) whereas, for compoud $\mathbf{3 b}$, it substantially decreases the retention factor $\left(\mathrm{k}_{1}=4.5\right.$ vs. 9.5$)$, while still providing acceptable enantioseparation parameters $\left(\alpha=1.1, R_{\mathrm{s}}=1.5\right)$ (entries 19 and 20). The less polar ketosulfones $\mathbf{2 a}$ and $\mathbf{2} \mathbf{b}$ have been bet- ter separated on CSP2, eluting with methanol $\left(5^{\circ} \mathrm{C}\right)$ (Table 1 , entries 13 and 16), as well as with $n$-hexane/2-propanol $=90 / 10\left(25^{\circ} \mathrm{C}\right)$ (entries 12 and 15). Under the same conditions, ketosulfones $\mathbf{1 a}$ and $\mathbf{1 b}$ have been also separated (entries 4, 5, 9, and 10). The use of methanol as eluent on CSP2 increases the solubility of the samples. In addition, it offers the possibility of an alternative chiral recognition

TABLE 3. HPLC behavior of the racemic compounds 15-25 on CSP1 and/or CSP2

\begin{tabular}{|c|c|c|c|c|c|c|c|c|c|}
\hline Entry & Compounds & CSPs & Mobile phase ${ }^{\mathrm{a}, \mathrm{b}}$ & $F R^{\mathrm{c}}$ & $t_{\mathrm{R} 1}(\min )$ & $t_{\mathrm{R} 2}(\min )$ & $k_{1}{ }^{\mathrm{d}}$ & $\alpha^{\mathrm{e}}$ & $R_{\mathrm{s}}$ \\
\hline 38 & 15 & 1 & Hexane $100 \%$ & 0.4 & 14.9 & 15.3 & 0.5 & 1.1 & 0.5 \\
\hline 39 & 15 & 2 & MeOH 100\% & 0.5 & 9.5 & 11.7 & 1.4 & 1.4 & 1.9 \\
\hline 40 & 16 & 1 & Hexane $100 \%$ & 1.0 & 27.3 & 44.4 & 5.5 & 1.7 & 3.0 \\
\hline 41 & 16 & 2 & MeOH 100\% & 0.5 & 11.0 & 12.0 & 1.8 & 1.2 & 1.0 \\
\hline 42 & 17 & 1 & Hexane $100 \%$ & 1.0 & 28.6 & 46.5 & 5.8 & 1.7 & 3.5 \\
\hline 43 & 18 & 2 & MeOH 100\% & 0.5 & 14.3 & 20.0 & 2.6 & 1.5 & 3.6 \\
\hline 44 & 19 & 1 & Hex:IPA (90:10) & 0.8 & 7.1 & 9.8 & 0.8 & 1.8 & 2.9 \\
\hline 45 & 20 & 1 & Hex:IPA (90:10) & 0.8 & 10.5 & & 1.7 & $\mathrm{NS}^{\mathrm{f}}$ & \\
\hline 46 & 21 & 1 & Hexane $100 \%$ & 0.4 & 11.1 & 11.9 & 0.1 & 1.6 & 0.8 \\
\hline 47 & 21 & 2 & MeOH 100\% & 0.5 & 9.2 & 12.0 & 1.3 & 1.5 & 2.7 \\
\hline 48 & 22 & 1 & Hexane $100 \%$ & 1.0 & 12.1 & 14.9 & 1.9 & 1.4 & 1.9 \\
\hline 49 & 22 & 2 & MeOH 100\% & 0.5 & 11.5 & 12.1 & 1.9 & 1.1 & 0.4 \\
\hline 50 & 23 & 1 & Hex:IPA (90:10) & 0.8 & 9.0 & 9.9 & 1.3 & 1.2 & 1.1 \\
\hline 51 & 24 & 1 & Hex:IPA (90:10) & 0.8 & 6.7 & 8.2 & 0.7 & 1.5 & 2.7 \\
\hline 52 & 24 & 2 & MeOH 100\% & 0.5 & 10.4 & 11.3 & 1.6 & 1.1 & 1.0 \\
\hline 53 & 25 & 1 & Hex:IPA (90:10) & 0.8 & 8.3 & 9.4 & 1.1 & 1.3 & 2.0 \\
\hline 54 & 25 & 2 & MeOH 100\% & 0.5 & 9.8 & 10.5 & 1.5 & 1.1 & 0.9 \\
\hline
\end{tabular}

${ }^{\mathrm{a}} \mathrm{Hex}$, hexane; IPA, 2-propanol; MeOH, methanol; TFA, trifluoroacetic acid.

${ }^{\mathrm{b}}$ Analyses on CSP2, using pure $\mathrm{MeOH}$ as eluant, were performed at $5^{\circ} \mathrm{C}$.

${ }^{c}$ Flow rate $(\mathrm{ml} / \mathrm{min}) ; F R=0.4, t_{0}=9.7 \mathrm{~min} ; F R=0.8, t_{0}=3.9 \mathrm{~min} ; F R=1.0, t_{0}=4.2$ for OD-H column; $F R=0.5, t_{0}=3.9 \mathrm{~min}$ for OT $(+)$ column.

${ }^{\mathrm{d}}$ Retention factor of the first-eluted enantiomer.

eSeparation factor.

${ }^{\mathrm{f}}$ Not separated. 
mechanism. In fact, compounds $\mathbf{2 a} / \mathbf{2} \mathbf{b}$ show reversed elution order in hexanic mobile phase, compared to what observed in methanol. Moreover, it is to be noted the high enantioselectivity $(\alpha=4.7)$ and the enantioresolution $\left(R_{\mathrm{S}}\right.$ $=9.2$ ) values obtained for ketosulfone 1a on CSP2 using methanol as eluent (entry 5). By adding TFA to the ternary mobile phase, ketosulfone $\mathbf{4}$ has been enantioseparated on CSP1 with good enantioselectivity $(\alpha=1.4)$ and high enantioresolution $\left(R_{\mathrm{S}}=3.2\right)$, showing, in addition, a suitable retention factor $\left(k_{1}=3.8\right)$ (entry 21 ).

Compounds of Table 2 were tested on CSP1 using either $n$-hexane $100 \%$ or $n$-hexane/2-propanol $=90 / 10$ or $n$-hexane/2-propanol/methanol $=91 / 6 / 3$. Bis(sulfone) 5 (entry 22) and alkenylsulfone 10a (entry 28) are well enantioseparated employing $n$-hexane/2-propanol/metha$\mathrm{nol}=91 / 6 / 3$. Under these or similar conditions, 2-phenylsulfonylbenzonorbornadiene $\mathbf{6}$ is partially separated $(\alpha=$ $\left.1.1, R_{\mathrm{S}}=0.6\right)$ (entry 23), as well as on CSP2 eluting with methanol at $5^{\circ} \mathrm{C}$ (entry 24). CSP2 (eluent methanol, $5^{\circ} \mathrm{C}$ ) afforded good enantioseparation for alkenylsulfone 10b $(\alpha$ =1.5) (entry 29), whereas a poorer enantioselectivity was obtained on CSP1 ( $\alpha=1.1$ ) (entry 28). Also sulfones 1114 are better separated on CSP2 (eluent methanol, $5^{\circ} \mathrm{C}$ ) than on CSP1 in hexane containing mobile phase. For sulfone 11, which was not well separated on CSP1 (entry $31)$, a good selectivity $(\alpha=1.2)$ did not yield high resolution on CSP2, showing, in fact, $R_{\mathrm{s}}=0.9$ (entry 32). The use of $n$-hexane/2-propanol/methanol $=91 / 6 / 3$ on CSP1 did not afford the enantioseparation of heterobromosulfones $\mathbf{8}$ and $\mathbf{9}$. These compounds were well retained on the polysaccharide stationary phase $\left[k_{1}(\mathbf{8})=4.2 ; k_{1}(\mathbf{9})\right.$ $=5.8$ ] but, when using $n$-hexane/2-propanol $=90 / 10$, showed poor enantioselectivity $(\alpha=1.1)$. Bromosulfone 7 was unseparated under the reported conditions (entry 25). The use of the hexane containing mobile phase on CSP2 gave no resolution for the sulfones reported in Table 2.

CSP1 and CSP2 exhibit complementary features towards bromoderivatives 15-19 and 21-25, which are well separated both on CSP1 and on CSP2, respectively under $n$-hexane or $n$-hexane/2-propanol $=90 / 10$ and methanol (see details in Table 3). Nevertheless, separation of tribromodimethoxybenzonorbornene $\mathbf{2 0}$ was unsuccessful. On CSP1, the ternary mobile phase $n$-hexane/2propanol/methanol $=91 / 6 / 3$ is unsuitable for the less polar compounds of Table 3. A poor enantioseparation and/ or enantioresolution were achieved on CSP1 only by using $n$-hexane $100 \%$ at low flow rate $(0.4 \mathrm{ml} / \mathrm{min})$ for bromoderivatives $15\left(\alpha=1.0, R_{\mathrm{S}}=0.5\right)$ (entry 38) and $21(\alpha=$ $1.6, R_{\mathrm{S}}=0.8$ ) (entry 46 ). The low values of the retention factors suggest that the compounds $\mathbf{1 5}\left(k_{1}=0.5\right)$ and $\mathbf{2 1}$ $\left(k_{1}=0.1\right)$ scarcely interact with the polysaccharide stationary phase (Fig. 6).

Nonpolar compounds $\mathbf{1 5}$ and $\mathbf{2 1}$ are better resolved on CSP2 when eluting with methanol (entries 39 and 47). On the contrary, the corresponding 5,8-dimethoxy derivatives $\mathbf{1 6}$ and 22 are better resolved on CSP1 in hexane containing mobile phase (entries 40 and 48) and show, on CSP2, low enantioselectivity and enantioresolution (entries 41 and 49). The enantioseparation of dibromo and tribromo derivatives 19, 23, 24, and 25 was achieved on CSP1 by Chirality DOI 10.1002/chir

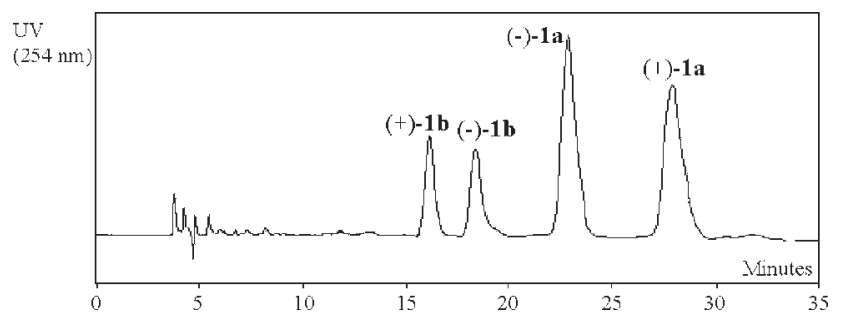

Fig. 5. Chromatogram of racemic compounds $\mathbf{1 a} / \mathbf{1 b}=70: 30$ on CSP1, $\lambda 254 \mathrm{~nm}$; mobile phase: $n$-hexane/IPA/MeOH $=91 / 6 / 3(0.1 \%$ TFA); flow rate $0.8 \mathrm{ml} / \mathrm{min}$.

using $n$-hexane/2-propanol $=90 / 10$ (pure hexane was unsuitable, showing scarce solvent ability for this class of compounds). In fact, this class of racemates was better resolved on CSP1 as compared to methanol elution on CSP2. The use of hexane containing mobile phase on CSP2 gave no resolution for these bromoderivatives.

\section{Influence of the Structure of Analytes on Chromatographic Separation}

Chiral recognition plays a relevant role in the field of enantioseparation. For liquid chromatography, the mechanism for the chiral recognition on CSPs can be clarified by means of chromatography, NMR spectroscopy, X-ray analysis, and computational methods. ${ }^{16}$ In the case of polymeric stationary phases, such as CSP1 and CSP2, it is difficult to evaluate a precise recognition mechanism because chiral polymers have very complex structures. The wealth of chromatographic data collected for compounds 1-25 has been used to understand the nature of the interactions between such compounds and CSP1 and CSP2: the impact of small modifications within the fixed carbon skeleton (Fig. 7) of bicyclo[2.2.x] $(x=1,2)$ and benzobicyclo[2.2.1] derivatives on the separation behavior has been investigated.

\section{CSP1}

It is well known that CSP1 has a left-handed 3/2-helical conformation with the glucose units regularly disposed along the helical axis. As reported by Okamoto et al., ${ }^{16}$ the chiral helical groove with its polar carbamate groups is preferably located inside whereas the hydrophobic aromatic groups are placed on outside the polymer chain. Polar enantiomers may predominantly interact with the carbamate residues in the groove through the formation of hydrogen bonds or other polar interactions. These interactions seem to be important for chiral discrimination, especially in normal-phase HPLC. In addition, the $\pi-\pi$ interactions $^{25}$ between the phenyl groups of the stationary phase and the aromatic groups of the analyte may play a role, because several nonpolar aromatic compounds have also been resolved. ${ }^{12}$

On the basis of these considerations, it may be suggested that the CSP1 interacts with the polar functional groups located on the bridged polycyclic skeleton, as shown in Figure 8. Ketosulfones 1, 3-4, which are resolved as well on CSP1, contain functional groups amenable to similar interactions. 

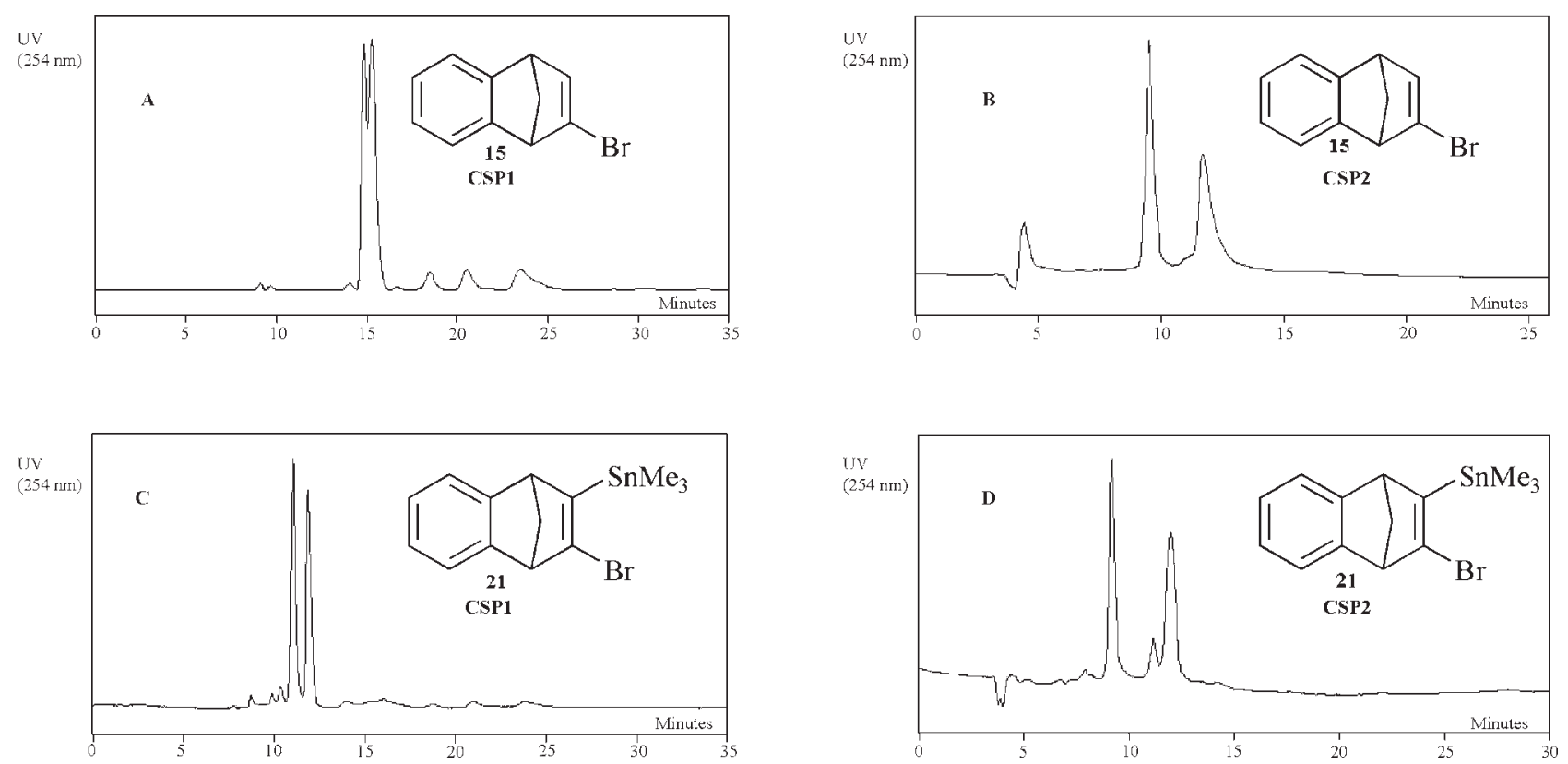

Fig. 6. Chromatograms of compounds $\mathbf{1 5}$ and $\mathbf{2 1}$ on CSP1 and CSP2, $\lambda 254 \mathrm{~nm}$. (A) $\mathbf{1 5}, \operatorname{CSP} 1, n$-hexane $=100 \%$, flow rate $0.4 \mathrm{ml} / \mathrm{min}$; (B) $\mathbf{1 5}$, $\mathrm{CSP} 2, \mathrm{MeOH}=100 \%$, flow rate $0.5 \mathrm{ml} / \mathrm{min}$; (C) 21, CSP1, $n$-hexane $=100 \%$, flow rate $0.4 \mathrm{ml} / \mathrm{min}$; (D) $21, \mathrm{CSP} 2, \mathrm{MeOH}=100 \%$, flow rate $0.5 \mathrm{ml} / \mathrm{min}$.

In the 2-phenylsulfonylbicyclo[2.2.1] series, it is likely that a strong hydrogen bond interaction between the ketone moiety at the $\mathrm{C} 3$ and the carbamate group of the CSP1 contributes to the efficient separation. In fact, substitution of the $\mathrm{O}$ atom of the ketone moiety with a methylene (10a) or a methyl group (12), which imparts less polarity to the $\mathrm{C} 3$ position, leads to a decrease of both enantioselectivity and enantioresolution. Moreover, analytes 10a and 12, which do not bear the ketone moiety, interact weakly with the CSP1, as inferred from the comparison of the retention factor values $\left[k_{1}(\mathbf{1 a})=8.5\right.$ vs. $k_{1}(\mathbf{1 0 a})=$ 1.7 and $k_{1}(\mathbf{1 2})=1.2$ ]. Failure to separate compound 7 might be ascribed to the enhanced steric hindrance at the $\mathrm{C} 2$ and $\mathrm{C} 3$ positions brought about by the bulky tolylsulfonyl and $\mathrm{Br}$ substituents. Furthermore, it is to be noted that the exocyclic double bond of compound 10a interacts with the stationary phase more efficiently than the endocyclic 2,3-double bond of derivative $\mathbf{1 2}$. In a similar fashion compounds such as 10b, 11-14, which possess an alkenyl or an alkyl substituent at C3, are not well separated on CSP1. This trend can also be observed in the case of $\mathbf{6}$ and 4 , in which the substituents at $\mathrm{C} 3$ are hydrogen atom and a ketone moiety, respectively.

The sulfonyl aromatic group of selectands may interact only with the hydrophobic 3,5-(dimethyl) substituted aromatic rings of CSP1 located outside the polymer chain. In this region the CSP1 exhibits poorer chiral recognition ability. In fact, we have found that racemic aromatic polycyclic hydrocarbons are better resolved with a different chiral stationary phase such as the Chiralpak OT(+). Rather, the phenylsulfonyl functionality seems to contribute to the interaction between analytes and the polysaccharide-based CSP $\left[k_{1}(\mathbf{4})=3.8, \alpha=1.4\right.$ vs. $k_{1}(\mathbf{6})=2.8, \alpha=$ 1.1]. This is also evident in the chromatographic behavior of 5, which presents two vicinal phenylsulfonyl groups and two additional aromatic nuclei at the apical zone. In fact, although retained as $\mathbf{1 a}\left[k_{1}(\mathbf{5})=8.0, k_{1}(\mathbf{1} \mathbf{a})=8.5\right]$, the bis(sulfone) 5 shows only a slight increase both of selectivity and resolution.

Furthermore, the presence of an heteroatom on the apical position of bicyclo[2.2.1] structures (8 and $\mathbf{9}$ vs. 7) increases the retention factor without affecting $\alpha$ and $R_{\mathrm{S}}$ values positively.

The stereochemistry of the phenylsulfonyl group located at $\mathrm{C} 2$ of the bicyclo[2.2.1] skeleton also plays a role, as can be seen by comparing the different chromatographic behavior of the endo (a) and exo (b) isomers (see

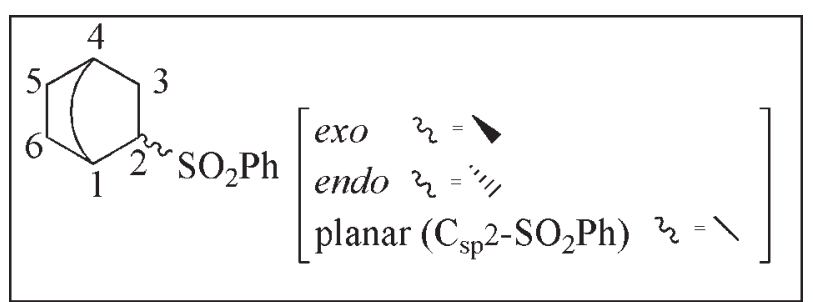

bicyclo[2.2.x] skeleton $(\mathrm{x}=1,2)$

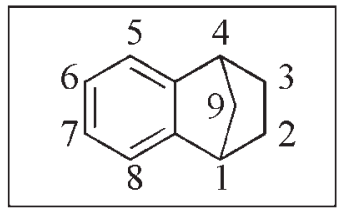

benzobicyclo[2.2.1] skeleton

Fig. 7. Fixed skeletons of racemates 1-25.

Chirality DOI 10.1002/chir 


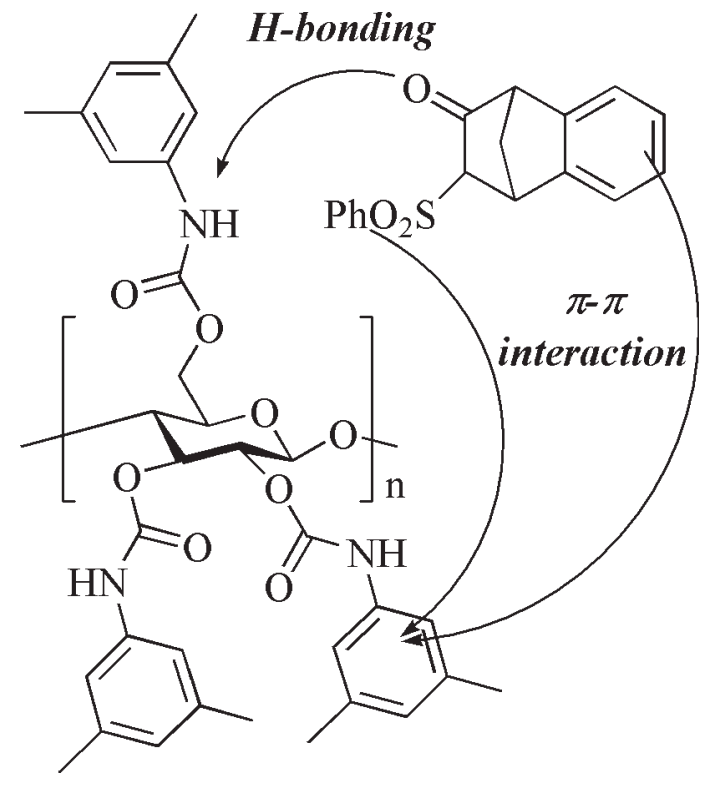

Fig. 8. Plausible interactions between CSP1 and the ketosulfone skeleton.

data of Table 1). In fact, epimers a are more retained and better separated than the corresponding epimers $\mathbf{b}$. The stereochemistry of the phenylsulfonyl group may influence the polarity of the ketone, changing its interaction ability. Methanol and TFA, when added to the mobile phase, respectively decrease the hydrogen bonding ability of the carbonyl functionality and weaken the adsorption of the racemic ketosulfone on the silica gel used as the support of the polymeric selector. These effects are more evident for $\mathbf{1 a}$ than for $\mathbf{1 b}$, suggesting that the ketone moiety of the exo epimer is less prone to interact with the stationary phase.

In the series of exo bicyclo[2.2.1] ketosulfones, the nature of the C5-C6 moiety plays a pivotal role. Enhanced selectivity and resolution were observed for 4 on CSP1, because of the presence of the $p$-dimethoxyaryl group, which formally replaces the double bond of $\mathbf{1 b}$. In $\mathbf{2 b}$, the lack of the double bond between $\mathrm{C} 5$ and $\mathrm{C} 6$ induces a drop of selectivity. The role of the $\pi$-electron density at $\mathrm{C} 5$ and $\mathrm{C} 6$ which proved to be crucial inside the chiral recognition process involving exo ketosulfones and the chiral sites of the stationary phase is self-evident. The chromatographic data, reported in Table 1, seem to suggest that, on the other hand, in the endo enantiomers only the ketone and the phenylsulfonyl functionalities are involved in the interaction with the stationary phase. On the basis of these considerations, it is suggested that the endo enantiomer might interact with the polar carbamate groups of the CSP1 helical groove through a "side" approach (Fig. 9A), in which the $\mathrm{C} 5-\mathrm{C} 6$ moiety scarcely contributes to retention and enantiodiscrimination. In the exo enantiomer, instead, an "endo-face" approach (Fig. 9B) might better play a role in the chiral recognition.

The chromatographic behavior of compound 3 shows that the bicyclo[2.2.2] and the bicyclo[2.2.1] skeletons oriChirality DOI 10.1002/chir ent themselves differently in the chiral enviroment of the CSP1. Probably, the enhanced steric hindrance onto the exo face changes the bond angles of the bicyclo[2.2.2] system, thus modifying all steric relationships.

The elution order of the enantiomers of $\mathbf{1}, \mathbf{2}$, and $\mathbf{3}$ has been determined, as shown in Table 1. Computational studies are in progress to rationalize these results.

It was difficult to resolve chiral aromatic bromoderivatives 15 and 18 by using CSP1. These bromo-substituted compounds contain only an aromatic functionality which is able to weakly interact with the stationary phase. Also compound 21, which contains the nonpolar trimethylstannyl group at C3, has been partially resolved. Dimethoxy derivative $\mathbf{2 2 , 1 6}$, and $\mathbf{1 7}$ are well enantioseparated with pure hexane. The mutual position of the two methoxy groups on the aromatic ring does not affect the chromatographic behaviour of bromoderivatives $\mathbf{1 6}$ and $\mathbf{1 7}$. The comparison of chromatographic parameters of compounds 15 and $\mathbf{1 6}$ with those of the corresponding bromostannyl derivatives 21 and 22 respectively is helpful to understand the role of the trimethylstannyl group inside the recognition process. In fact, the bulky trimethylstannyl group decreases the retention ability of compound $\mathbf{2 1}$ on the CSP1. On the other hand, the $\mathrm{Me}_{3} \mathrm{Sn}$-moiety may exert a selective repulsive interaction with the stationary phase, thus increasing the enantioselectivity and the enantioresolution. These findings suggest that the bromobenzonorbornadiene structure approaches the stationary phase by the endo face (Fig. 10), involving not only a strong interaction with the aromatic ring but also a moderate interaction with the 2,3-double bond. On the contrary if a "side" approach takes place, aforementioned effects related to the $\mathrm{Me}_{3} \mathrm{Sn}$-moiety would not be observed.

The dibromo and tribromo derivatives 19, 20, 23, 24, and 25, eluted using hexane/2-propanol $=90 / 10$, are poor retained on CSP1. Among these, compounds 23, which presents two endo-bromo substituents, is the poorer enantioseparated ( $\alpha=1.2, R_{\mathrm{S}}=2.1$ ) (Table 3 , entry 49 ), thus confirming that the postulated "endo face" approach of the analytes to the stationary phases is operative.

\section{CSP2}

Chiralpak OT(+) is the first commercialized CSP derived from a synthetic chiral polymer. In particular, CSP2 is able to resolve compounds lacking polar functional groups, ${ }^{14,15}$ whose separation would be difficult to realize by other conventional methods. In fact the (+)-PTrMA exhibits a high chiral recognition ability for various racemic compounds containing only aromatic systems. Better separation attained in reversed-phase system using methanol as eluent than in normal-phase system using hexanic medium, because the hydrophobic $\pi-\pi$ interactions between the side groups (trityl group) of the polymeric stationary phase and nonpolar aromatic groups of the racemic solute appear important. In hexanic mixture the driving force for the enantioseparation is mainly the hydrogen bond interactions between the enantiomers and the chiral polymer.

The 29 evaluated compounds contain either an aromatic nucleus bearing a sulfonyl moiety, or an aromatic system which is part of the benzobyciclo[2.2.1] structure. The 


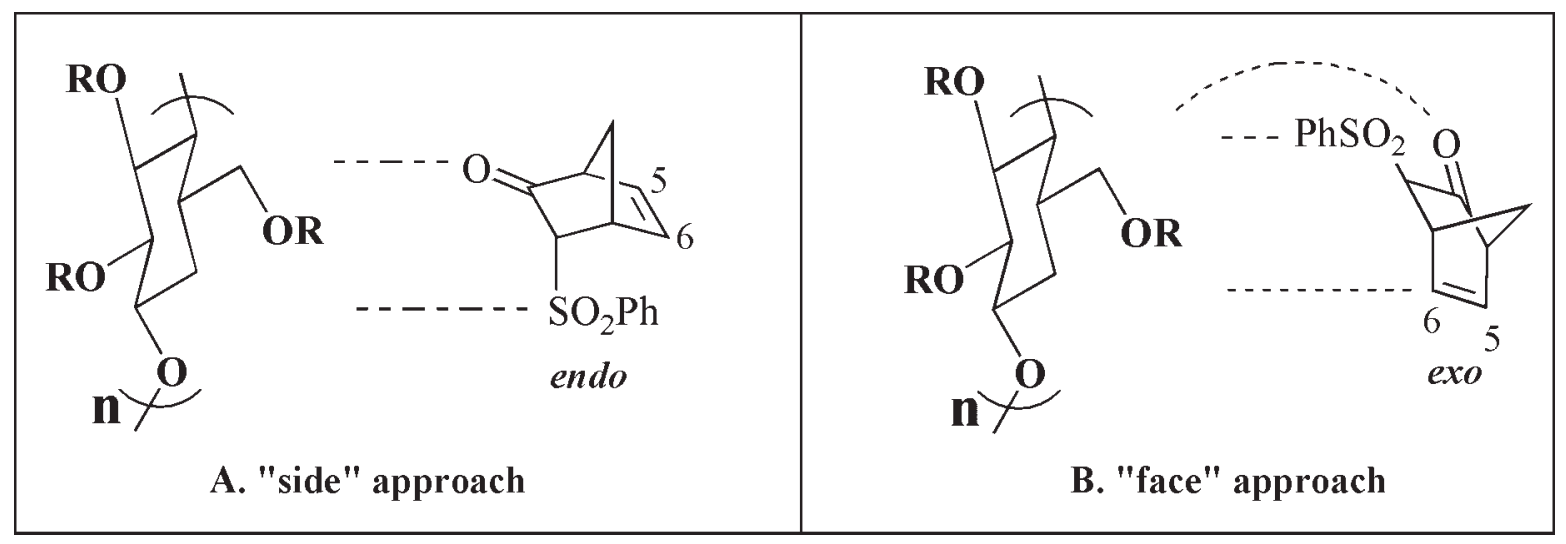

Fig. 9. Proposed chiral recognition model for the interaction between $\mathbf{1}$ and CSP1.

chromatographic behavior of these compounds seems to suggest a recognition mechanism in which the steric approach of the aromatic ring of the selectand to the stationary phase plays a critical role.

In the case of phenylsulfonyl compounds, enhancing the bulkiness of the C3-substituent by means of a methylene (10b) or a methyl group (12) or a bromine atom (7) alters the enantioselectivity and enantioresolution as compared to $\mathbf{1 b}$ which contains a carbonyl moiety at C3. It is evident that the steric hindrance exerted by the substituent at C3 close to the phenylsulfonyl group decreases the ability of the sulfonyl aromatic ring to establish hydrophobic interactions.

The enantiomers of $\mathbf{1 a}$ are better resolved than the corresponding enantiomers of $\mathbf{1 b}$, showing very good enantioselectivity and enantioresolution values $\left(\alpha=4.7, R_{\mathrm{s}}=\right.$ 9.2) (Table 1, entry 5). This fact suggest that the stereochemistry of the phenylsulfonyl group at $\mathrm{C} 2$ might play a crucial role in the recognition mechanism between the bicyclo[2.2.1] structure and the chiral polymeric stationary phase. Furthermore, in $\mathbf{1 a}$, the 5,6-double bond and the aromatic moiety both contribute to the $\pi$ interaction ability

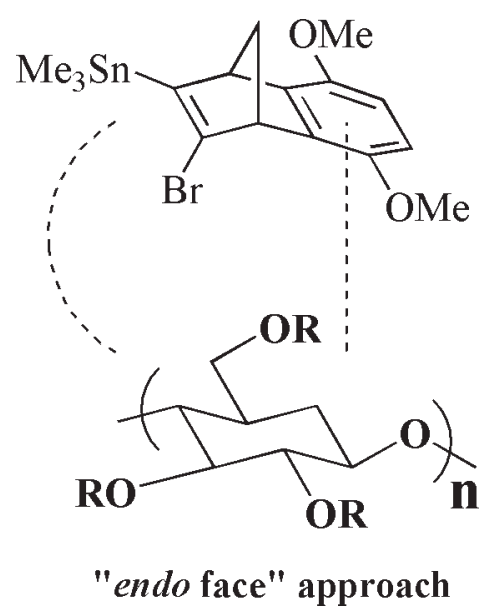

Fig. 10. Proposed interaction model between bromobenzonorbornadienes and CSP1. of the endo face of the polycyclic structure. On the contrary, in $\mathbf{1 b}$ the mutual position of the sulfonyl aromatic ring and of the 5,6-double bond is unsuitable for such cooperation, as in the case of compounds $\mathbf{2}$. In addition, the observed reversed elution order of $\mathbf{2 a}$ (Table 1) indicates that the 5,6-double bond of $\mathbf{1 a}$ is strongly implicated in the resolution mechanism on CSP2.

As to concerns the benzobicyclo[2.2.1] compounds reported in Table 3 , the recognition mechanism involves the benzocondensed portion of the structure. In this case, the steric hindrance of the aromatic moiety is responsible for the poorer enantioseparation (Fig. 11).

Di- and tribromobenzobicyclo[2.2.1] derivatives cannot interact effectively with the stationary phase and consequently a low selectivity was achieved on CSP2. Compound $\mathbf{6}$, which contains both the sulfonyl substituted aromatic ring and the benzofused one shows poor enantioseparation and enantioresolution $\left(\alpha=1.1, R_{\mathrm{s}}=0.2\right)$ on CSP2 (Table 2, entry 24). The steric hindrance of the two bulky group probably decreases the efficiency of the hydrophobic interactions.

\section{CONCLUSION}

Under the described conditions, the enantiomers of 27 of 29 racemic bridged polycyclic compounds have been successfully enantioseparated on at least one of the two CSPs. Small variations in the chemical structure of the analyzed polycyclic racemate have a relevant impact on the chromatographic behavior. Both electronic and steric properties of the substituents affect the resolution of the racemates. Attractive interactions are supposed to be mainly responsible for separations on CSP1. For CSP2 in methanolic reversed phase system, hydrophobic interaction mechanism has been postulated. Chromatographic parameters $(k, \alpha)$, related to the thermodynamic properties of the diastereoisomeric complexes generated by the interaction between the analytes and the binding sites of CSP have been calculated. By comparing these data, we have been able to evaluate how the nature and the position of a certain functional group influence the chromatographic separation. Given a defined chiral analyte inside a consid- 
<smiles>BrC1=CC2CC1c1cc3ccccc3cc12</smiles><smiles>BrC1=CC2CC1c1ccccc12</smiles>

18 $\alpha=1.5, \mathrm{R}_{\mathrm{s}}=3.6$
15

$$
\alpha=1.4, \mathrm{R}_{\mathrm{s}}=1.9
$$<smiles>COc1ccc(OC)c2c1C1C=C(Br)C2C1</smiles>

16

$\alpha=1.2, \mathrm{R}_{\mathrm{s}}=1.0$<smiles>COc1cc2c(cc1OC)C1C(Br)=CCC21</smiles>

17

unseparated

Fig. 11. Comparison of chromatographic parameters of the compounds 15, 16, 17, and 18 .

ered family of polycyclic compounds, this information provides an empirical and simple recognition model for the selection of a suitable column.

\section{LITERATURE CITED}

1. Weinshenker NM, Stephenson R. Basic hydrogen peroxide cleavage of a bicyclic ketone. A new procedure for a prostaglandin intermediate. J Am Chem Soc 1972;94:3741.

2. Arjona O, Csákÿ AG, Plumet J. Sequential metathesis in oxa- and azanorbornene derivatives. Eur J Org Chem 2003;4:611-622.

3. Paquette LA, Zhou R. Synthesis of enantiopure C2-symmetric VERDI disulfonamides and their application to the catalytic enantioselective addition of diethylzinc to aromatic and aliphatic aldehydes. J Org Chem 1999;64:7929-7934.

4. Chen Z, Trudell ML. Chemistry of 7-azabicyclo[2.2.1]hepta-2,5-dienes, 7-azabicyclo[2.2.1]hept-2-enes and 7-azabicyclo[2.2.1] heptanes. Chem Rev 1996;96:1179-1193.

5. Cossu S, De Lucchi O, Peluso P, Volpicelli R. Enantioselective synthesis of polycyclic ketones by desymmetrization of bis(phenylsulfonyl)alkenes with chiral alcoholates. Control of the absolute configuration by a simple modification of the chiral auxiliary. Tetrahedron Lett 1999;40:8705-8709.

6. Cossu S, Peluso P. Diastereoselective desymmetrization of meso bis (phenylsulfonyl) polycyclic alkenes promoted by $\mathrm{C}_{2}$ symmetric chiral diolates: direct access to optically pure ketals and ketones. J Org Chem 2005;1:1-17.

7. Cossu S, Peluso P. Desymmetrization of meso 7-aza-2,3-bis (phenylsulfonyl) bicyclo[2.2.1]hept-2-ene: a re-examination. Kinetic resolution of racemic 3-arylsulfonyl-7-aza-2-bromobicyclo[2.2.1]hepta-2,5-dienes. Tetrahedron Lett 2006;47:4015-4018.

8. Cossu S, Peluso P, Moretto F, Marchetti M. Conversion of $\gamma$-substituted bicyclo[2.2.1] (Z)-vinylsulfones to the corresponding (E)-allylsulfones. Tetrahedron Lett 2006;47:2253-2256.

9. Peluso P, Greco C, De Lucchi O, Cossu S. Synthesis of 2-mono- and 2,3disubstituted polycyclic alkenes. Eur J Org Chem 2002;23:4024-4031.

10. Cossu S, Cimenti C, Peluso P, Paulon A, De Lucchi O. Enantiomeric discrimination in a reiterative domino coupling process: $\mathrm{Cu}^{\mathrm{I}}$-mediated syn cyclotrimerization of racemic polycyclic trimethylstannyl bromonorbornadienes. Angew Chem Int Ed 2001;40:4086-4089.
11. Okamoto Y, Aburatani R, Kaida Y, Hatada K. Direct optical resolution of carboxylic acids by chiral HPLC on tris(3,5-dimethylphenylcarbamate)s of cellulose and amylose. Chem Lett 1988;1125-1128.

12. Yashima E. Polysaccharide-based chiral stationary phases for highperformance liquid chromatographic enantioseparation. J Chromatogr A 2001;906:105-125.

13. Piras P, Roussel C, Pierrot-Sanders J. Reviewing mobile phases used on Chiralcel OD through an application of data mining tools to CHIRBASE database. J Chromatogr A 2001;906:443-458.

14. Yuki H, Okamoto Y, Okamoto I. Resolution of racemic compounds by optically active poly(triphenylmethyl methacrylate). J Am Chem Soc 1980;102:6356-6358.

15. Nakano T. Optically active synthetic polymers as chiral stationary phases in HPLC. J Chromatogr A 2001;906:205-225.

16. Okamoto Y, Yashima E. Polysaccharide derivatives for chromatographic separation of enantiomers. Angew Chem Int Ed 1998;37:1020-1043.

17. Yashima E, Yamamoto C, Okamoto Y. Polysaccharide-based chiral LC columns. Synlett 1998;4:344-360.

18. Cossu S, De Lucchi O. (Z)- and (E)-1-chloro-1,2-bis(phenylsulfonyl)ethylenes: synthons of bis(phenylsulfonyl)acetylene and of terminal acetylenes in cycloaddition reactions. Gazz Chim Ital 1990;120:569-576.

19. Zonta C, Cossu S, De Lucchi O. Synthesis of benzotri(benzonorbornadienes) (BTBNDs): rigid, cup-shaped molecules with high electron density within the cavity. Eur J Org Chem 2000;10:1965-1971.

20. Perrin DD, Armarego WLF. Purification of laboratory chemicals, 3rd ed. Great Britain: Pergamon Press; 1998.

21. Cossu S, De Lucchi O, Fabris F, Ballini R, Bosica G. A Michael route to acetals and thioacetals: preparation of acetals (thioacetals) of 2-sulfonylacetaldehyde from alkynyl and other unsatured aryl sulfones. Synthesis 1996;12:1481-1484.

22. Dastan A, Demir U, Balci M. Functionalization of benzonorbornadiene: high-temperature bromination and electrochemical oxidation. J Org Chem 1994;59:6534-6538.

23. Dastan A, Taskesenligil Y, Tumer F, Balci M. High temperature bromination. VIII. Bromination of homobenzonorbornadiene. Tetrahedron 1996;52:14005-14020.

24. Balci M, Güney M, Dastan A, Azizoğlu A. The effect of the double bond pyramidalization on the mode of the bromination reaction: bromination of benzobicyclononadiene. J Org Chem 2007,72:4756-4762.

25. Pirkle WH, Liu Y. On the relevance of face-to-edge $\pi-\pi$ interactions to chiral recognition. J Chromatogr A 1996;749:19-24. 